\title{
Evaluation of Enterococcus faecium NRRL B-2354 as a surrogate for Salmonella enterica in milk powders at different storage times and temperatures
}

\author{
Xinyao Wei, ${ }^{1} \odot$ Shantanu Agarwal, ${ }^{2} \odot$ and Jeyamkondan Subbiah ${ }^{1,3,4 *} \odot$ \\ ${ }^{1}$ Department of Food Science and Technology, University of Nebraska, Lincoln 68588 \\ ${ }^{2}$ Mars Wrigley Confectionery, Chicago, IL 60560 \\ ${ }^{3}$ Department of Biological Systems Engineering, University of Nebraska, Lincoln 68583 \\ ${ }^{4}$ Department of Food Science and Technology, University of Arkansas, Fayetteville 72704
}

\section{ABSTRACT}

While the increase in thermal resistance of microorganisms at reduced water activity is demonstrated for low-moisture food products, the effect of storage time on the thermal resistance of microorganisms in lowmoisture foods is not well established. As low-moisture foods are stored for long periods and are used as ingredients, cross-contamination can occur at any time period before the lethality step. Therefore, this study was designed to investigate the effect of storage time (30, 60, and 90 d) on the thermal resistance of Salmonella and Enterococcus faecium NRRL B-2354 in milk powders at a low water activity of 0.10 (conservative level). In this study, 2 milk powders, whole milk powder (WMP) and nonfat dry milk (NFDM), were inoculated with a 5-serotype Salmonella cocktail or E. faecium and equilibrated to a water activity of 0.10 . The thermal resistance of Salmonella and E. faecium in WMP and NFDM were determined at different storage times (30, 60 , and $90 \mathrm{~d}$ ) at $85^{\circ} \mathrm{C}$. The storage time had no effect on the thermal inactivation kinetics of Salmonella within $90 \mathrm{~d}$ of storage at $85^{\circ} \mathrm{C}$. In the second part of this study, isothermal treatments were also conducted at higher temperatures $\left(90\right.$ and $\left.95^{\circ} \mathrm{C}\right)$ to evaluate the suitability of E. faecium as a surrogate for Salmonella in milk powders. The $D$-values of Salmonella in WMP with $30 \mathrm{~d}$ of storage at 85,90 , and $95^{\circ} \mathrm{C}$ were $7.98,3.35$, and $1.68 \mathrm{~min}$. The corresponding values for E. faecium were $16.96,7.90$, and $4.16 \mathrm{~min}$. Higher $D$-values of $E$. faecium indicates that it is a conservative surrogate. Similar results were found for NFDM. In general, $D$ values of both microorganisms are slightly higher in NFDM than WMP. Two primary models (log-linear and Weibull) were compared for their goodness-of-fit.

\footnotetext{
Received June 30, 2020

Accepted September 2, 2020.

*Corresponding author: jsubbiah@uark.edu
}

The Weibull model was found to be more appropriate than the log-linear model. This study provides valuable information for establishing process validation for the pasteurization of milk powders.

Key words: surrogate, Weibull, model analysis, process validation, low-moisture food

\section{INTRODUCTION}

Food products with water activities $<0.70$ are categorized as low water activity foods (Blessington et al., 2013). Most of the foodborne pathogens require water activity $>0.9$ for proper growth; thus, they were historically not a concern in low water activity foods. However, the survival of Salmonella in low water activity foods, such as almond (CDC, 2004), milk powder (CDC, 1993; Angulo et al., 2008), peanut butter (CDC, 2009), and black pepper (CDC, 2010), have resulted in several foodborne outbreaks in the United States, indicating that low water activity food can no longer be considered as inherently microbiologically safe.

Milk is a nutrient-rich liquid that is often spray-dried into powder forms for a longer shelf-life. Milk powders are commonly used as ingredients in many food products including ready-to-eat foods, such as confectionery, drink mixes, seasoning, nutritional bars, and dry blend infant formula. However, no pathogen lethality step is applied to eliminate foodborne pathogens in milk powders after spray drying (LiCari and Potter, 1970), which could potentially result in serious food safety issues. For instance, 37 babies in France were known to have fallen sick due to the presence of Salmonella Agona in powdered milk in 2018 (Marler, 2018). Several recalls and outbreaks have also been linked to Salmonella-contaminated dry milk powder products (Park et al., 2004; Brouard et al., 2007; RodríguezUrrego et al., 2010; Jourdan-da Silva et al., 2018).

After spray drying of milk powders, there is a risk of cross-contamination through poor postprocessing 
practices, such as poor environmental sanitation, inappropriate storage conditions, or mishandling during transportation (Podolak et al., 2010). Before further processing of milk powders, especially for ready-to-eat foods, an effective pasteurization process should be integrated to minimize the risk of contamination of final products.

As required by the US FDA (2018), validation studies are required to scientifically demonstrate that processing technologies effectively limit the hazards they are designed to address. Also, due to the difficulty of directly introducing the target pathogen into the processing plant, the use of a surrogate to replace the pathogen is recommended by FDA (2013) to conduct the validation study in the industrial processing plant. Several studies (Bianchini et al., 2014; Liu et al., 2018; Verma et al., 2018; Wei et al., 2018) have previously demonstrated that Enterococcus faecium NRRL B-2354 is a suitable surrogate for Salmonella during thermal processing of low water activity foods.

In commercial practice, ingredients such as milk powders are usually stored at $23^{\circ} \mathrm{C}$ for a long period before usage. It has been reported that high storage temperature $\left(45^{\circ} \mathrm{C}\right)$ could greatly affect lipid oxidation in whole milk powder (WMP), and the maximum level of free radicals was detected after $47 \mathrm{~d}$ of storage at $45^{\circ} \mathrm{C}$ (Stapelfeldt et al., 1997). According to US Dairy Export Council (2017), the typical storage time for WMP is 6 to 9 mo at room conditions $\left(<27^{\circ} \mathrm{C},<65 \%\right.$ relative humidity). Flavor deterioration of WMP has been reported to occur after 3 mo of storage (Drake et al., 2003). However, the effect of storage time on the thermal inactivation kinetics of Salmonella in milk powders is currently unknown. Therefore, it is important to understand the effect of storage time on thermal inactivation kinetics for process validation studies. It is also important to evaluate the suitability of surrogate at different storage times and temperatures.

The overall goal of this study is to evaluate the effect of storage time on thermal inactivation kinetics of $\mathrm{Sal}$ monella and E. faecium NRRL B-2354 in milk powders. The specific objectives were to (1) determine the effect of storage time $(30,60$, and $90 \mathrm{~d})$ on the thermal inactivation kinetics of Salmonella and E. faecium NRRL B-2354 in milk powders at $85^{\circ} \mathrm{C}$ and water activity of 0.10 , and (2) evaluate E. faecium NRRL B-2354 as a surrogate for Salmonella at different temperatures (85, 90 , and $95^{\circ} \mathrm{C}$ ) after $30 \mathrm{~d}$ of storage of milk powders at a water activity of 0.10 .

\section{MATERIALS AND METHODS}

\section{Milk Powder Products}

Three batches of grade A pasteurized WMP and nonfat dry milk (NFDM) from different production lots were received from Mars Inc. (McLean, VA). The milk powders were stored inside polyethylene bags and held at ambient temperature $\left(23 \pm 2^{\circ} \mathrm{C}\right)$ before inoculation. On receiving the samples, the proximate analysis and background microorganism tests were conducted as described in Wei et al. (2020a). A water activity meter (4TE, METER Group, Pullman, WA) was used to measure the water activity of milk powders at $25^{\circ} \mathrm{C}$.

\section{Inoculum Preparation}

The details of the bacterial serotypes used in this study are described in Table 1. A Salmonella cocktail, consisting of 5 serotypes of Salmonella enterica ssp. enterica that were previously isolated from different foodborne outbreaks, was used to inoculate both powder samples. Enterococcus faecium NRRL B-2354 was used to inoculate both powder samples for surrogate tests.

The lawn-based pelletized inoculum method was used to prepare the inoculum based on a standard procedure as described in Hildebrandt et al. (2016), which yields a stable bacterial population before isothermal treatment and consistent $D$-value. The frozen stock of each bacteria was thawed at $37^{\circ} \mathrm{C}$ for $5 \mathrm{~min}$, then was subjected to 2 sequential transfers $\left(24 \mathrm{~h}\right.$ at $\left.37^{\circ} \mathrm{C}\right)$ in $10 \mathrm{~mL}$ of trypticase soy broth (TSB; Becton, Dickinson and Company, Franklin Lakes, NJ) with $0.6 \%$ (wt/vol) yeast extract (YE; Becton, Dickinson and Company). A loop ( 10

Table 1. Bacterial serotypes used in this study

\begin{tabular}{llll}
\hline Bacterial name & Source $^{1}$ & Related outbreak & \multirow{2}{*}{ Reference } \\
\hline Salmonella Agona 447967 & FDA, ORA Regional Laboratory (Jefferson, AR) & Oats cereal & CDC, 1998 \\
Salmonella Montevideo 488275 & FDA, ORA Regional Laboratory (Jefferson, AR) & Black and red pepper & CDC, 2010 \\
Salmonella Mbandaka 698538 & FDA, ORA Regional Laboratory (Jefferson, AR) & Sprouts & Jackson et al., 2013 \\
Salmonella Reading Moff 180418 & FDA Culture Collection (Bedford Park, IL) & Alfalfa sprout & CDC, 2016 \\
Salmonella Tennessee K4643 & University of Georgia (Athens, GA) & Peanut butter & CDC, 2007 \\
Enterococcus faecium NRRL B-2354 & USDA, ARS (Peoria, IL) & Almond Board of \\
& & & California, 2014 \\
\hline
\end{tabular}

${ }^{1} \mathrm{FDA}=$ Food and Drug Administration; ORA = Office of Regulatory Affairs; ARS = Agricultural Research Service. 
$\mu \mathrm{L})$ of the incubated culture was streaked onto tryptic soy agar (TSA; Becton, Dickinson and Company) supplemented with $0.6 \%$ (wt/wt) YE and incubated at $37^{\circ} \mathrm{C}$ for $24 \mathrm{~h}$ to prepare the working stock plate. A $10-\mu \mathrm{L}$ loop was used to harvest one isolated colony from a working stock plate and was then transferred to $10 \mathrm{~mL}$ of TSBYE and incubated for $24 \mathrm{~h}$ at $37^{\circ} \mathrm{C}$. The incubated culture $(0.1 \mathrm{~mL})$ was then spread-plated onto a TSAYE plate and incubated for $24 \mathrm{~h}$ at $37^{\circ} \mathrm{C}$. The grown bacterial lawn was then harvested with 3 $\mathrm{mL}$ of $0.1 \%$ buffered peptone water (Becton, Dickinson and Company) with an L-shaped spreader. By mixing the equal amount of lawn from each Salmonella serotypes, the Salmonella cocktail inoculum was prepared with the bacterial population of approximately 1,010 cfu/mL. Similarly, E. faecium NRRL B-2354 inoculum was prepared with the bacterial population of approximately $10^{9} \mathrm{cfu} / \mathrm{mL}$.

\section{Milk Powder Inoculation and Equilibration}

The WMP or NFDM from each batch was weighed $(100 \mathrm{~g})$ and transferred to a resealable 1-gallon polyethylene bag. A sterile 15-mL centrifuge tube (Thermo Fisher Scientific, Rochester, NY) with a finger-operated spray head contained a $10-\mathrm{mL}$ aliquot of the prepared Salmonella cocktail or E. faecium NRRL B-2354 inoculum was used to spray-inoculate both milk powder samples. The inoculated sample was then mixed by hand for 5 min to manually detach powders that were stuck to the inner lining of the bag. Subsequently, the sample was transferred into a sterile Whirl-Pak bag (2.04 L, Nasco, Fort Atkinson, WI) and then placed in a paddle mixer (9000471, Neutec Group Inc., Farmingdale, NY) and mixed for $20 \mathrm{~min}$ to homogenize the inoculum distribution and minimize the clumps. The mixed inoculated sample ( $5 \mathrm{~mm}$ thickness) was then placed on a sterile aluminum tray $(230 \times 300 \times 15 \mathrm{~mm})$ and transferred into a custom-made relative humidity chamber (Lau and Subbiah, 2020a) set to a target relative humidity of $10 \%$ to equilibrate the inoculated sample to a water activity of 0.10 at $25^{\circ} \mathrm{C}$. Based on the previous study (Wei et al., 2020a), a low water activity of 0.10 was selected, which could represent the worstcase scenario where Salmonella exhibits high thermal resistance. This low water activity (0.10) represents a conservative study, as Salmonella resistance is higher at lower water activity. After $5 \mathrm{~d}$ of equilibration in the chamber, the inoculated sample was packed into heatsealable aluminized pouches $(7.62 \mathrm{~cm} \times 7.62 \mathrm{~cm} \times 0.10$ cm, IMPAK Corporation, Los Angeles, CA) in quantities of approximately $2 \mathrm{~g}$ and then sealed for storage at $23^{\circ} \mathrm{C}$ for 30,60 , and $90 \mathrm{~d}$. The whole packing process was conducted inside the relative humidity chamber to ensure a minimal change in the water activity.

\section{Determination of Thermal Resistance at Different Storage Times}

Stored inoculated milk samples were sampled on 30 , 60 , and $90 \mathrm{~d}$ to evaluate the effect of storage time on the heat resistance of Salmonella and E. faecium. Isothermal treatment was conducted at $85^{\circ} \mathrm{C}$ by using the custom-designed thermal death time (TDT) sandwich (Lau and Subbiah, 2020b) for both WMP and NFDM to obtain the isothermal death curve of Salmonella and E. faecium at $85^{\circ} \mathrm{C}$. The TDT sandwich has 2 resistive heating elements that could apply dry heat to samples. Each packed inoculated sample was placed in between the 2 heating elements in one TDT sandwich unit for isothermal treatment of one time and temperature combination.

Before conducting the isothermal treatment, the come-up time was measured in triplicates by a type $\mathrm{T}$ thermocouple (5TC-TT-T-40-36, Omega Engineering Inc., Norwalk, CT) with an accuracy of $\pm 0.5^{\circ} \mathrm{C}$ inserted to the inside center of an aluminized pouch. The comeup time was the average time required for the sample to be heated to $84.5^{\circ} \mathrm{C}$ by the TDT sandwiches plus twice the standard deviation, which would ensure that at least $95 \%$ of TDT sandwiches would reach at least $84.5^{\circ} \mathrm{C}$ at time zero in the inactivation curve.

Six equally spaced time points including time zero were used for the isothermal treatment of inoculated samples to obtain thermal death curves for Salmonella or E. faecium in both WMP and NFDM. Immediately after each treatment, the treated pouch was transferred into an ice-water bath $\left(0^{\circ} \mathrm{C}\right)$ for at least $1 \mathrm{~min}$ before it was enumerated for bacterial survivors.

\section{Surrogate Evaluation at Different Temperatures}

To evaluate the suitability of E. faecium as a surrogate for Salmonella at different temperatures, isothermal treatments at the higher temperatures (90 and $95^{\circ} \mathrm{C}$ ) were conducted for Salmonella or E. faecium in inoculated milk powders. Based on the results of the storage study as described in the previous section, a single storage time was used to determine the thermal inactivation kinetics for both bacteria at higher temperatures. Inoculated samples were isothermally treated by the TDT sandwiches as described in the previous section to obtain thermal inactivation curves for Salmonella or E. faecium in both WMP and NFDM at 
90 and $95^{\circ} \mathrm{C}$. All isothermal treatments for inoculated WMP and NFDM were performed in 3 independent replicates by using inoculated samples from each batch.

\section{Bacterial Enumeration}

Enumeration was performed as previously described (Wei et al., 2019). Briefly, the Salmonella or E. faecium survivors in the thermally treated sample were enumerated by serially 10 -fold diluting samples in $0.1 \%$ buffered peptone water and were then spread-plated onto TSAYE supplemented with $0.05 \%$ (wt/vol) ammonium iron citrate (Sigma-Aldrich Co., St. Louis, MO), and $0.03 \%$ (wt/vol) sodium thiosulfate (mTSA; Fisher Chemical, Fair Lawn, NJ) for Salmonella or TSAYE supplemented with $0.05 \%$ (wt/vol) ammonium iron citrate, and $0.025 \%$ (wt/vol) esculin hydrate (eTSA; Acros Organics, Morris Plains, NJ) for E. faecium and incubated for $24 \mathrm{~h}$ at $37^{\circ} \mathrm{C}$ (Smith et al., 2016; Liu et al., 2017; Wei et al., 2020b). Colonies with a black center were counted as Salmonella on incubated mTSA plates and black colonies were counted as E. faecium on incubated eTSA plates, respectively. The untreated WMP or NFDM samples were enumerated as a control to monitor the bacterial population change during the $90 \mathrm{~d}$ of storage.

\section{Curve Fitting of The Survivor Models}

The Salmonella or E. faecium survivors in both milk powders were fitted with 2 primary inactivation models, the log-linear model [1] and the Weibull-type model [2] as described in Peleg and Cole (1998):

$$
\begin{aligned}
\log _{10}\left(\frac{N}{N_{0}}\right) & =-\frac{t}{D}, \\
\log _{10}\left(\frac{N}{N_{0}}\right) & =-\left(\frac{t}{\delta}\right)^{\beta},
\end{aligned}
$$

where $N$ and $N_{0}(\mathrm{cfu} / \mathrm{g})$ are the Salmonella or E. faecium survivors at time $t$ and $0 ; t$ is the instantaneous time of the thermal treatment (min); $D$ is the decimal reduction time, which is the time required to reduce the microbial population by 10 -fold; $\delta$ ( $\mathrm{min}$ ) is the scale parameter; and $\beta$ is the shape parameter of the Weibull inactivation curve, where $\beta>1$ indicates a concave downward trend, $\beta<1$ indicates a concave upward trend of the inactivation curve, and $\beta=1$ indicates a linear trend.

The $z$-value is defined as the increase in temperature required to achieve a $90 \%$ reduction of the decimal re- duction time $D$ and was determined by the following equation:

$$
z=\frac{T_{2}-T_{1}}{\log _{10} D_{T_{1}}-\log _{10} D_{T_{2}}}
$$

where $\log _{10} D_{T_{1}}-\log _{10} D_{T_{2}}$ are the $D$-values at temperature $T_{1}$ and $T_{2}$, respectively.

The bacterial survival data for each isothermal treatment were fitted to Equations [1] and [2] using the Levenberg-Marquardt algorithm for nonlinear least squares regression as implemented in the curve_fit function of the Python SciPy library (Newville et al., 2015). The statistical significance of differences between different storage times and different milk powder products were analyzed using Fisher's least significant difference test as implemented in the LSD_test function of the R agricolae library (de Mendiburu and de Mendiburu, 2019).

\section{Global Models}

The log-linear and Weibull models were also globally fitted across all 3 storage times. To evaluate the appropriateness of model fitting, model selection analyses were performed using root mean squared error (RMSE) and corrected Akaike information criteria (AIC ; Motulsky and Christopoulos, 2003):

$$
\operatorname{RMSE}=\sqrt{\frac{\sum_{i=1}^{n}\left[\log _{10}(N)_{\text {observed }, i}-\log _{10}(N)_{\text {predicted }, i}\right]^{2}}{n}},
$$

$$
\mathrm{AICc}=\operatorname{nln}\left(\frac{S S}{n}\right)+2 K+\frac{2 K(K+1)}{n-K-1},
$$

where $\log _{10}(N)_{\text {observed,i }}$ is the observed log population, $\log _{10}(N)_{\text {predicted }, i}$ is the predicted log population from the model, and $n$ is the total number of observations, $S S$ is the sum of squares of the residuals, and $K$ is the number of parameters being estimated plus 1 . Lower RMSE and $\mathrm{AIC}_{\mathrm{c}}$ values indicate that the model prediction is more likely to be correct for the experimental data. According to Motulsky and Christopoulos (2003), the percent likelihood of a given model is more correct, which can be estimated using the following equation:

$$
\text { Probability }(\text { model A over B })=\frac{e^{\left(\frac{A I C_{c, B}-A I C_{c, A}}{2}\right)}}{1+e^{\left(\frac{A I C_{c, B}-A I C_{c, A}}{2}\right)}} .
$$




\section{RESULTS AND DISCUSSION}

\section{Survival of Salmonella and E. faecium in WMP and NFDM}

The bacterial populations of Salmonella and E. faecium in the prepared inoculum were 10.84 and 9.92 $\log \mathrm{cfu} / \mathrm{mL}$, respectively. Immediately after inoculation, Salmonella and E. faecium populations were determined to be 8.13 and $8.86 \mathrm{log} \mathrm{cfu} / \mathrm{g}$ in WMP and 8.25 and $8.92 \mathrm{log} \mathrm{cfu} / \mathrm{g}$ in NFDM, respectively. After $24 \mathrm{~h}$ equilibration in the relative humidity chamber, the inoculated samples were equilibrated to the water activity level of $0.10 \pm 0.01$, and the Salmonella and $E$. faecium population were dropped to 7.75 and $8.61 \mathrm{log}$ $\mathrm{cfu} / \mathrm{g}$ in WMP and 7.86 and $8.78 \mathrm{log} \mathrm{cfu} / \mathrm{g}$ in NFDM, respectively. The standard deviations of 3 subsamples from inoculated WMP and NFDM were determined to be 0.18 and $0.15 \log \mathrm{cfu} / \mathrm{g}$, respectively, which indicated a good homogeneity of the inoculated samples.

The survival results of Salmonella and E. faecium in WMP and NFDM are shown in Figure 1. During $90 \mathrm{~d}$ of storage, the reductions of Salmonella in WMP and NFDM were observed to be 0.79 and $0.86 \log \mathrm{cfu} / \mathrm{g}$, whereas the reductions of E. faecium in WMP and NFDM were observed to be 0.10 and $0.16 \mathrm{log} \mathrm{cfu} / \mathrm{g}$ (Figure 1). Most of the decrease in the initial population of Salmonella was observed in the first $30 \mathrm{~d}$ of storage. The results in this study showed that Salmonella in milk powder experienced a rapid death rate in the first few weeks of storage followed by a slower death rate are in agreement with several published studies (LiCari and Potter, 1970; Lian et al., 2015). A similar reduction in Salmonella population has been observed during the postinoculation process of low water activity foods, such as black pepper (Wei et al., 2018, 2019), cumin seeds (Chen et al., 2019), egg white powder (Wei et al., 2020b), almond (Abd et al., 2012), wheat flour (Forghani et al., 2019), and walnut kernel (Blessington et al., 2012). Salmonella cells need time to adapt to a low water activity environment. Thus, a higher death rate was observed during the adaption period and then the death rate leveled off in the remaining storage time.

According to Lian et al., (2015), the population of Salmonella in skim milk powder dropped by $4.23,4.69$, and $5.58 \mathrm{log} \mathrm{cfu} / \mathrm{g}$ after $2 \mathrm{mo}$ of storage at the water activity of $0.33,0.53$, and 0.81 , respectively. As the water activity of milk powder is this study was much lower at 0.10 , a much lower reduction of $0.86 \mathrm{log} \mathrm{cfu} / \mathrm{g}$ of the Salmonella population in NFDM after $90 \mathrm{~d}$ of storage was observed. Enhanced survivability of Salmonella was observed at lower water activity level during the storage of low water activity foods, as desiccated conditions have been reported to increase survivability
(Jung and Beuchat, 1999; Kataoka et al., 2014; Lian et al., 2015). Differences in reductions of Salmonella found in this study when compared with Lian et al. (2015) may also be due to differences in inoculum protocols (Hildebrandt et al., 2016).

Similar to Salmonella, several other foodborne pathogens, such as Enterobacter sakazakii (Gurtler and Beuchat, 2007) and Listeria monocytogenes (Ballom et al., 2020) have been shown to survive well in milk powders at a reduced water activity level. Therefore, the longterm survival of foodborne pathogens in milk powders should be of concern to the dairy industry and it is important to have a kill step to enhance the safety of milk powders.

\section{Effect of Storage Time on the Thermal Resistance of Salmonella and E. faecium}

The effect of storage time on the thermal resistance of Salmonella and E. faecium was investigated at $85^{\circ} \mathrm{C}$ and at the water activity of 0.1 . The low water activity of 0.1 was selected in this study to represent the worst-case scenario, as increased thermal resistance of Salmonella has been reported at reduced water activity levels in both WMP and NFDM (Wei et al., 2020a). The isothermal treatment temperature of $85^{\circ} \mathrm{C}$ was chosen because there was a minimum quality impact on sensory properties of milk powders at this temperature.

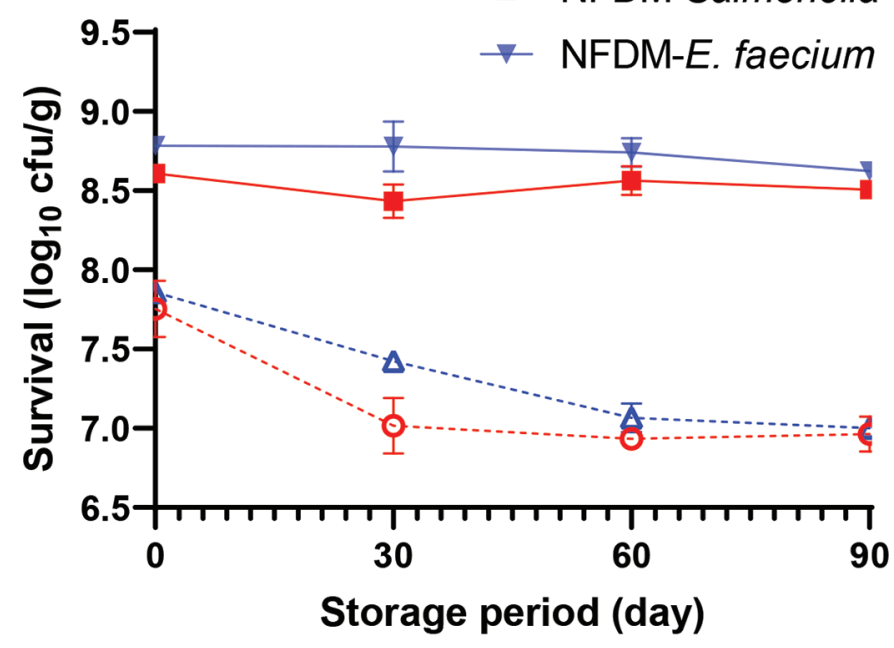

Figure 1. Viability of Salmonella and Enterococcus faecium population in whole milk powder (WMP) and nonfat dry milk (NFDM) during storage period $\left(23^{\circ} \mathrm{C}\right)$. Error bars indicate $1 \mathrm{SD}$ of 3 subsamples. 
Table 2. Effect of storage time on model parameter estimates for the log-linear and Weibull models at $85^{\circ} \mathrm{C}^{1}$

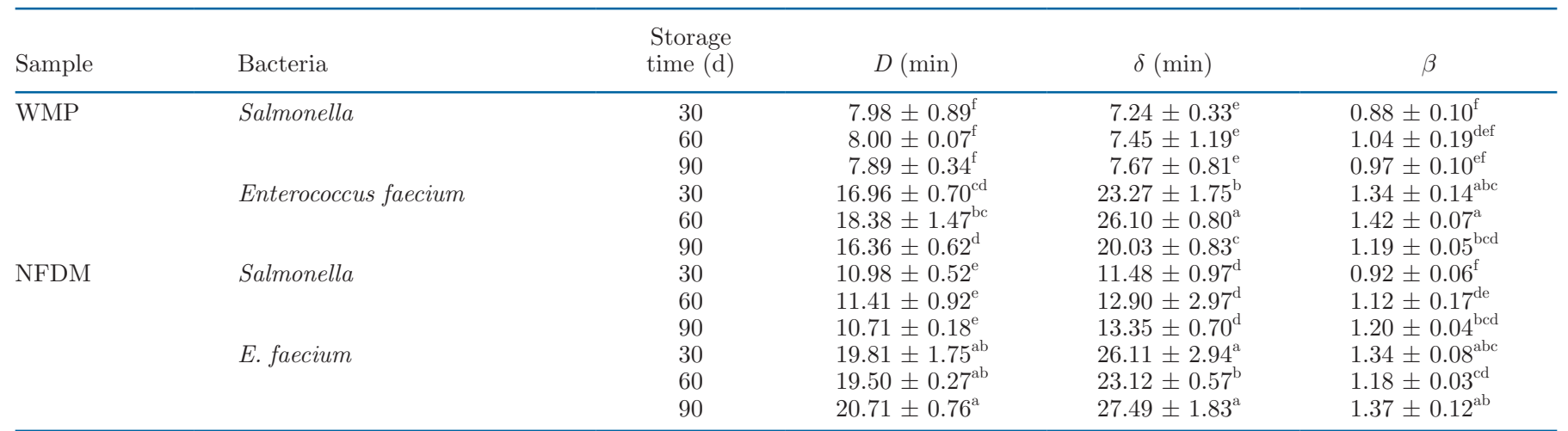

${ }^{\mathrm{a}-\mathrm{f}}$ Values with differing superscript letters are significantly different within a column $(P<0.05)$.

${ }^{1} D=$ decimal reduction time; $\delta=$ scale parameter for Weibull model; $\beta=$ shape parameter for Weibull model; WMP $=$ whole milk powder; $\mathrm{NFDM}=$ nonfat dry milk. Values are mean \pm SD of triplicates.

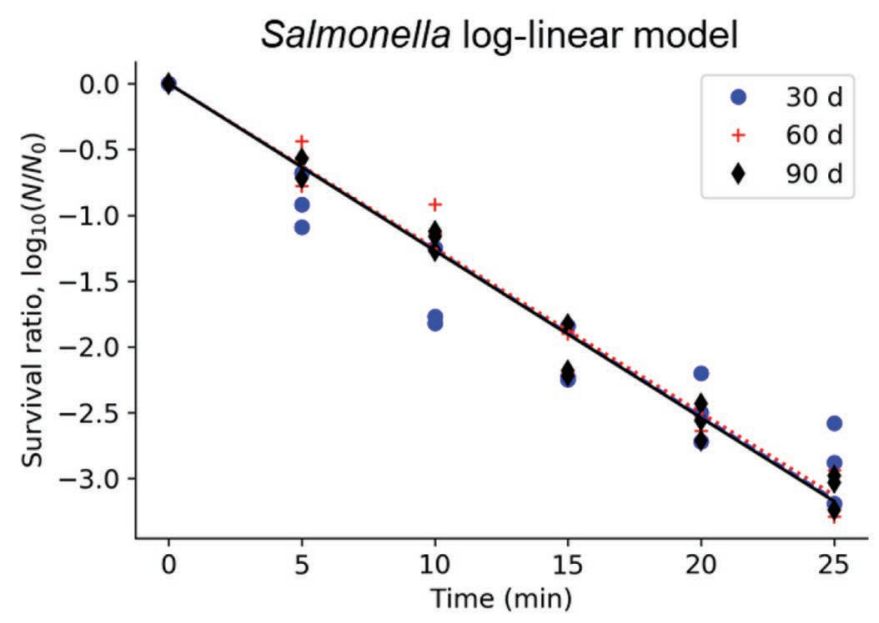

E. faecium log-linear model

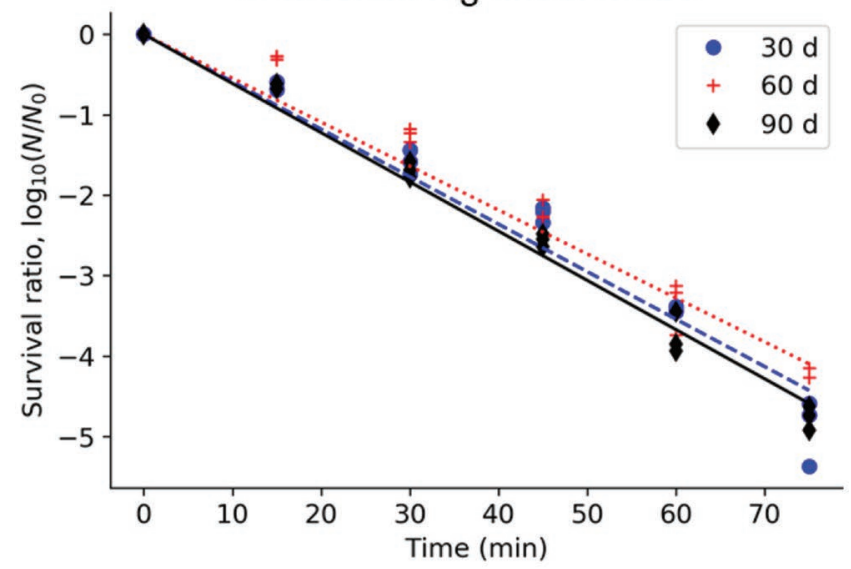

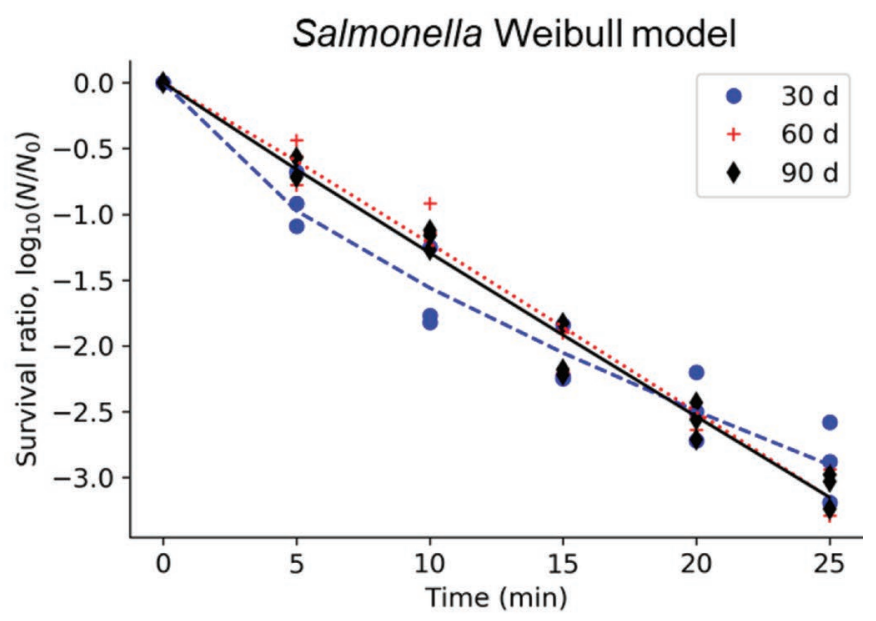

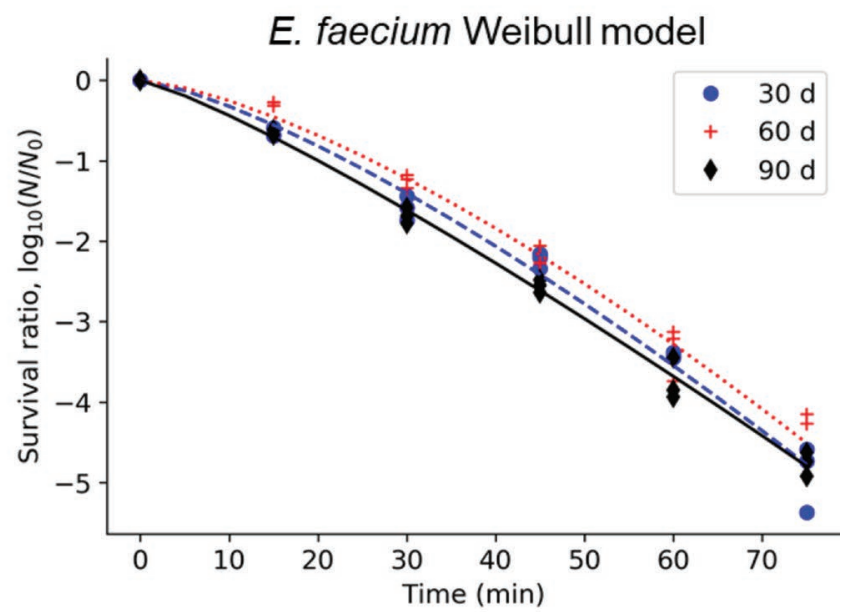

Figure 2. Experimental and predicted survival of Salmonella and Enterococcus faecium in whole milk powder stored for $30 \mathrm{~d}(\bullet$, dashed lines), $60 \mathrm{~d}$ ( + , dotted lines), and $90 \mathrm{~d}\left(\diamond\right.$, solid lines) at $85^{\circ} \mathrm{C} . N$ and $N_{0}$ (cfu/g) are the Salmonella or E. faecium survivors at time $t$ and 0 . 
The model parameters of the log-linear model and the Weibull model for both WMP and NFDM were compared across the 3 storage times in Table 2. For both WMP and NFDM, the $D$-values of Salmonella were not significantly $(P<0.05)$ different among the storage times. Similarly, there were no significant $(P<0.05)$ differences of $D$-values among the storage times for the Weibull model parameters of both WMP and NFDM. The fitted models were plotted against the inactivation data in Figure 2 for WMP and Figure 3 for NFDM. The proximity (closeness) and similar curvatures (slope and shape) of the curves for different storage times also reveal the similarity in model parameters.

These results suggest that the thermal resistance of Salmonella is not affected by storage time. Abd et al. (2012) and Limcharoenchat et al. (2019) also reported that the storage time had no effect on the heat resistance of Salmonella in almonds, which is in agreement with this study. Similarly, the thermal resistance of L. monocytogenes adapted to NFDM (Ballom et al., 2020), chicken meat powder, and pet food (Rachon et al., 2016) was shown to remain constant during prolonged storage.

Therefore, a conclusion can be drawn that when viable cells of Salmonella reach stable status in the low water activity environment, their heat resistance would not significantly change with increasing storage time up to $90 \mathrm{~d}$. Although Salmonella can survive in low water activity foods for extended periods, this study suggests that their resistance to thermal treatment does not change significantly during the storage of $90 \mathrm{~d}$ at $85^{\circ} \mathrm{C}$. While the effect of storage period on thermal resistance at other pasteurization temperatures needs to be evaluated, this result implies that the pasteurization protocol does not need to consider the prior storage period up to $90 \mathrm{~d}$ at $85^{\circ} \mathrm{C}$. This may increase the flexibility
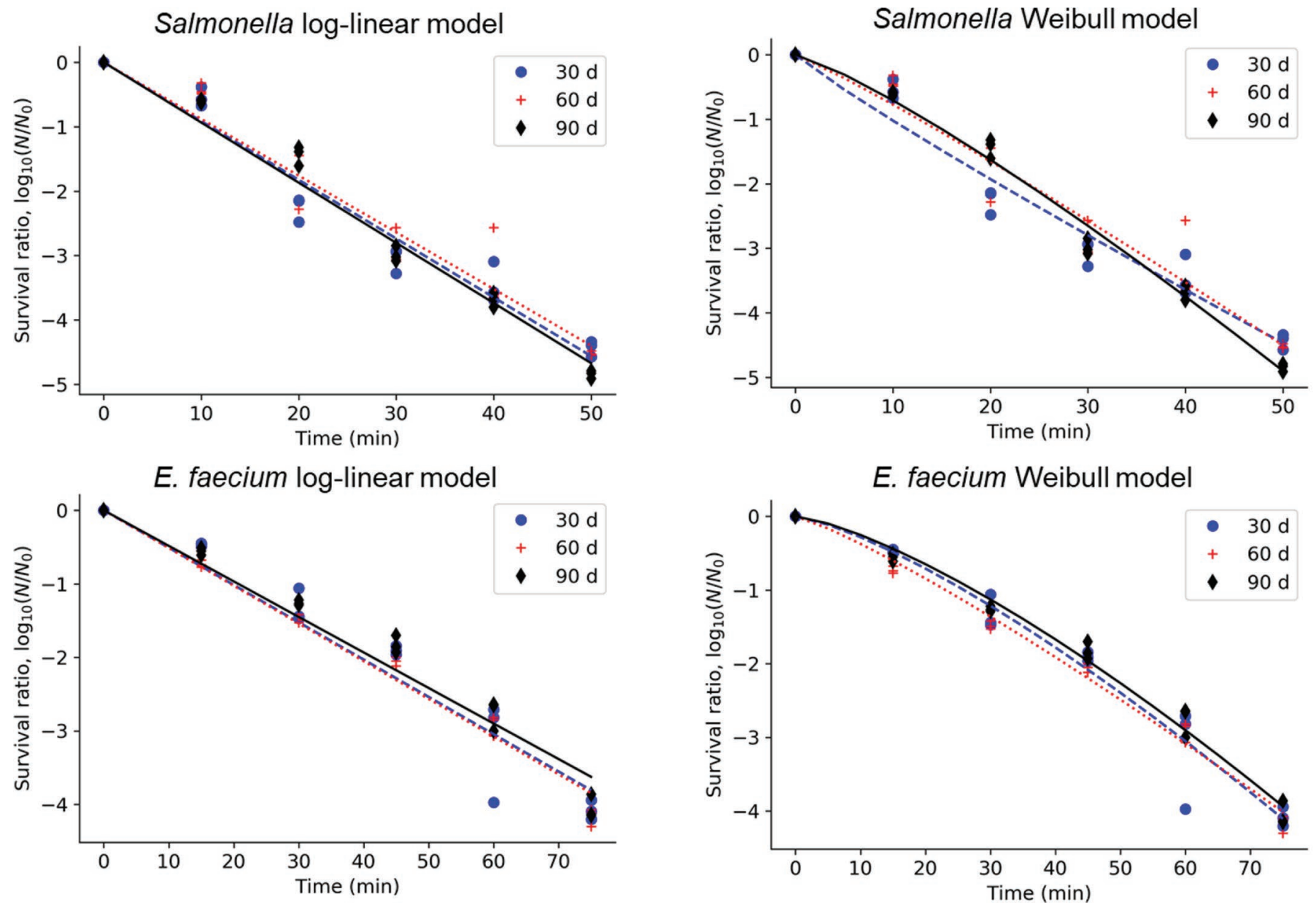

Figure 3. Experimental and predicted survival of Salmonella and Enterococcus faecium in nonfat dry milk stored for $30 \mathrm{~d}$ (•, dashed lines), $60 \mathrm{~d}$ (+, dotted lines), and $90 \mathrm{~d}\left(\diamond\right.$, solid lines) at $85^{\circ} \mathrm{C} . N$ and $N_{0}(\mathrm{cfu} / \mathrm{g})$ are the Salmonella or E. faecium survivors at time $t$ and 0. 


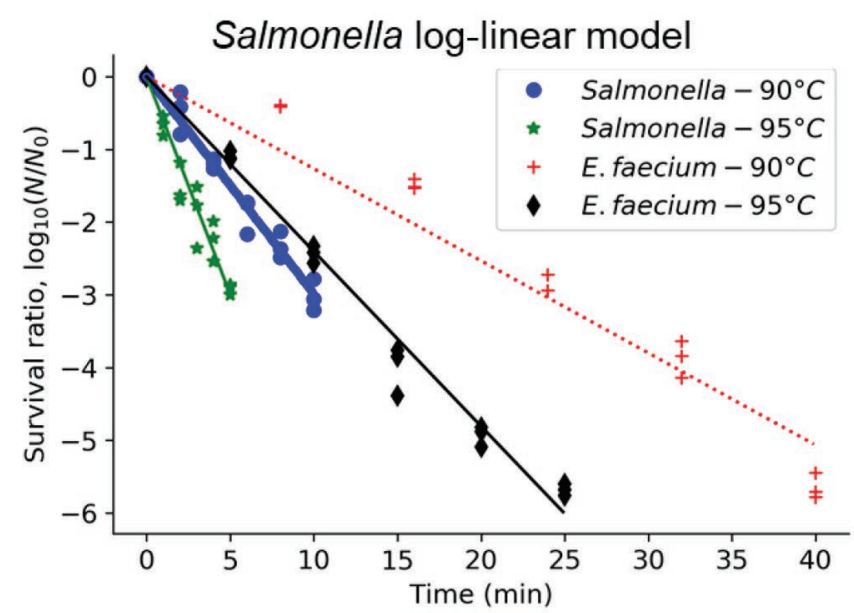

E. faecium log-linear model

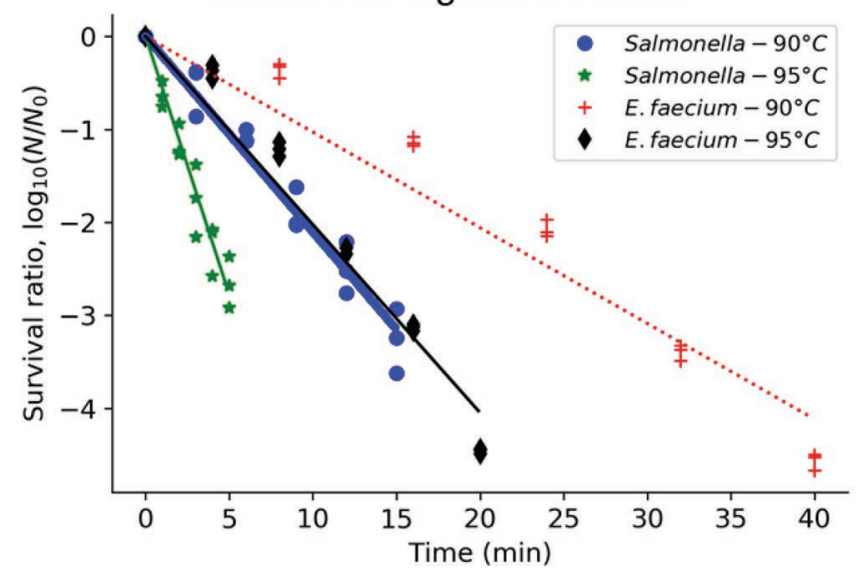

Salmonella Weibull model

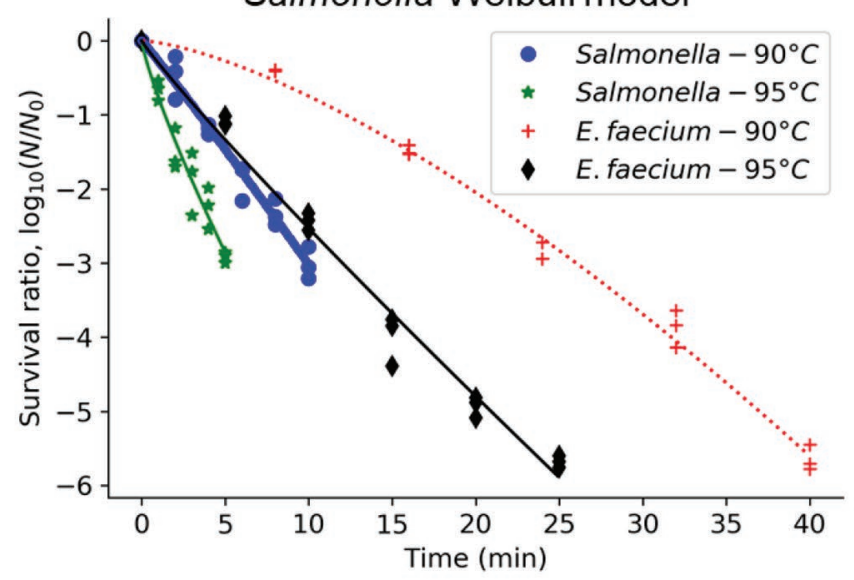

E. faecium Weibull model

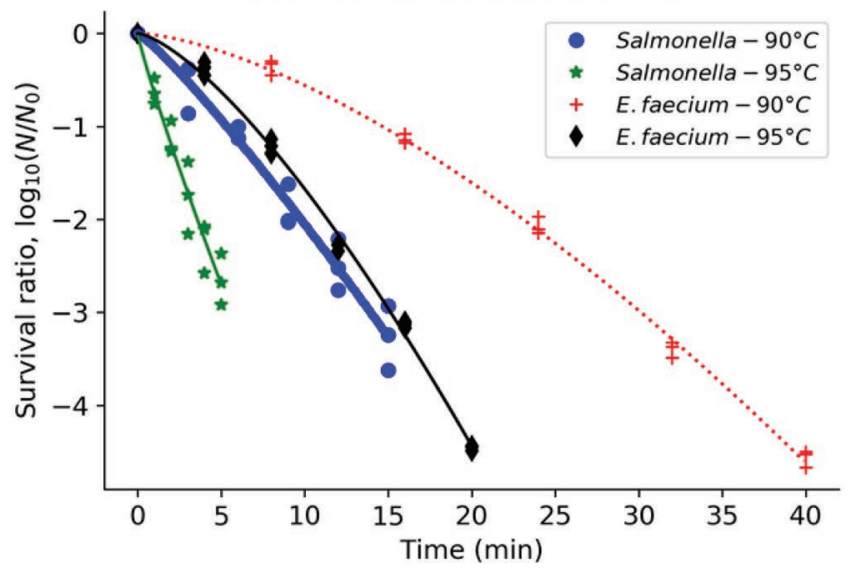

Figure 4. Log-linear and Weibull models fitted to Salmonella and Enterococcus faecium inactivation data of 90 and $95^{\circ} \mathrm{C}$. Salmonella-90 ${ }^{\circ} \mathrm{C}$

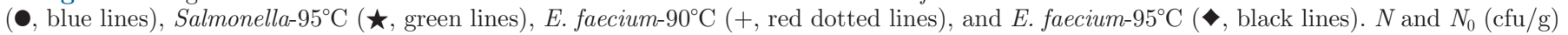
are the Salmonella or E. faecium survivors at time $t$ and 0 .

Table 3. Effect of temperature on model parameter estimates for the log-linear and Weibull models after 1 mo of storage ${ }^{1}$

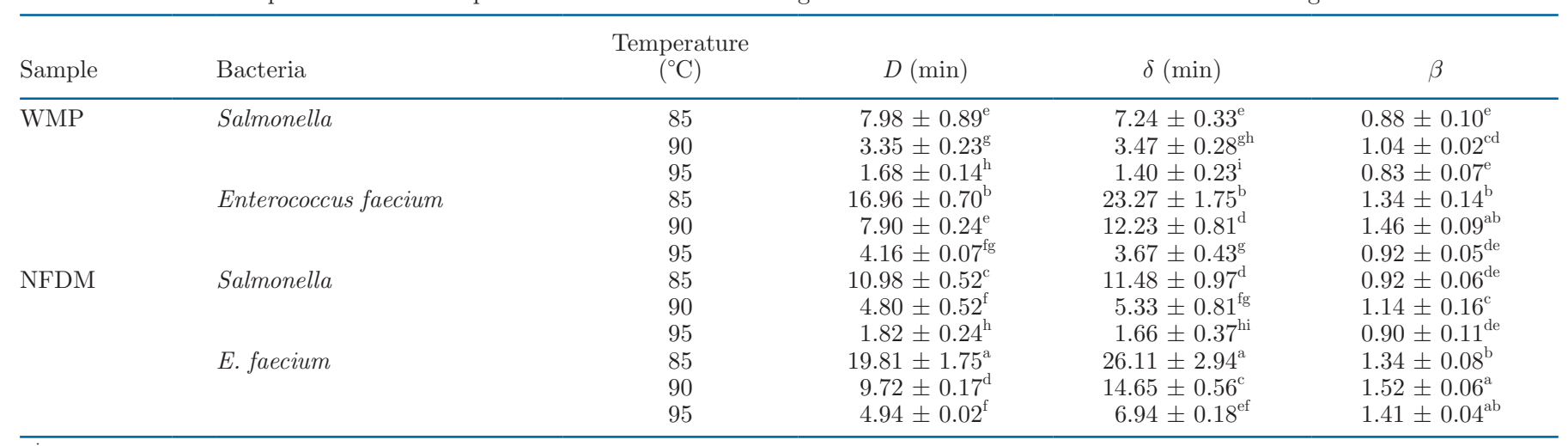

${ }^{\mathrm{a}-\mathrm{i}}$ Values with differing superscript letters are significantly different within a column $(P<0.05)$.

${ }^{1} D=$ decimal reduction time; $\delta=$ scale parameter for Weibull model; $\beta=$ shape parameter for Weibull model; WMP $=$ whole milk powder; $\mathrm{NFDM}=$ nonfat dry milk. Values are mean \pm SD of triplicates. 
Table 4. Model parameter estimates for the log-linear and Weibull models globally fitted across all storage times at $85^{\circ} \mathrm{C}^{1}$

\begin{tabular}{|c|c|c|c|c|c|c|c|}
\hline Sample & Bacteria & Model & $D$ or $\delta(\min )$ & $\beta$ & $\begin{array}{c}\text { RMSE } \\
\left(\log _{10} \mathrm{cfu} / \mathrm{g}\right)\end{array}$ & $\mathrm{AIC}_{\mathrm{c}}$ & Probability \\
\hline \multirow[t]{3}{*}{ WMP } & Salmonella & Log-linear & $7.93(0.32)$ & - & 0.21 & -165.80 & 0.04 \\
\hline & & Weibull & $7.07(0.33)$ & $0.89(0.04)$ & 0.20 & -172.15 & 0.96 \\
\hline & & Weibull & $23.05(0.62)$ & $1.31(0.04)$ & 0.23 & -158.52 & $\sim 1$ \\
\hline \multirow[t]{2}{*}{ NFDM } & Salmonella & Log-linear & $11.00(0.30)$ & - & 0.32 & -119.55 & 0.28 \\
\hline & & Weibull & $11.9(0.34)$ & $1.07(0.03)$ & 0.32 & -121.42 & 0.72 \\
\hline
\end{tabular}

${ }^{1} D=$ decimal reduction time; $\delta=$ scale parameter for Weibull model; $\beta=$ shape parameter for Weibull model; RMSE $=$ root mean square error; $\mathrm{AIC}_{\mathrm{c}}=$ corrected Akaike information criteria; WMP $=$ whole milk powder; NFDM = nonfat dry milk. Microbial populations from 3 storage periods and triplicates were simultaneously used to fit model to estimate model parameters along with the SE of estimate reported in parentheses.

of the application of process control if the results from the effect of storage period hold at other pasteurization temperatures.

In Table 2 , it has been shown that $D$ and $\delta$ values of E. faecium were significantly higher $(P<0.05)$ than Salmonella at the same storage condition in both WMP and NFDM. This demonstrated that E. faecium consistently exhibited greater thermal resistance $(P<$ 0.05) than Salmonella during the storage of WMP and NFDM.

\section{Thermal Inactivation Kinetics of Salmonella and $E$. faecium in WMP and NFDM}

Because storage time (90 d) had no effect on the heat resistance of Salmonella, the isothermal treatments at

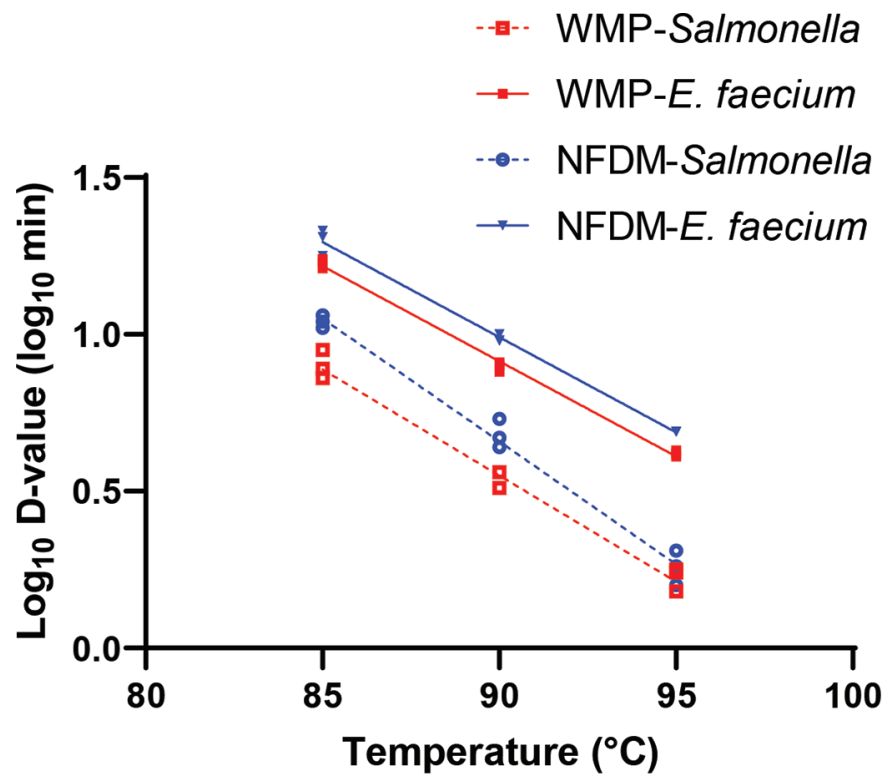

Figure 5. Thermal resistance constants (z-values) of Salmonella and Enterococcus faecium in whole milk powder (WMP) and nonfat dry milk (NFDM).
90 and $95^{\circ} \mathrm{C}$ were conducted by using the inoculated samples at d 30 of storage time to acquire thermal inactivation kinetics of Salmonella and E. faecium. The bacterial inactivation data were fitted to both log-linear and Weibull models in Figure 4. The model parameters for both WMP and NFDM are summarized in Table 3. For both Salmonella and E. faecium, $D$ and $\delta$ values were found to significantly $(P<0.05)$ decrease with increased temperature, which indicated that a higher microbial reduction could be achieved at a higher temperature for the same treatment time. Significantly higher $(P<0.05) D$ and $\delta$ values of $E$. faecium were also observed at 85,90 , and $95^{\circ} \mathrm{C}$ than Salmonella. Similarly, Liu et al. (2019) conducted isothermal treatments for NFDM with storage time of $48 \mathrm{~h}$ after inoculation and found that the decline of Salmonella exceeded that of $E$. faecium during isothermal treatment of NFDM at all 3 temperatures $\left(85,90\right.$, and $\left.95^{\circ} \mathrm{C}\right)$. These results suggest that E. faecium is a suitable nonpathogenic surrogate for Salmonella in the thermal processing of milk powder at different process temperatures with $30 \mathrm{~d}$ of storage.

Figure 5 shows the effect of temperature on the $D$ values of Salmonella and E. faecium in dairy powders. The $z$-values of Salmonella and E. faecium were determined to be 14.77 and $16.39^{\circ} \mathrm{C}$ for WMP and 12.82 and $16.58^{\circ} \mathrm{C}$ for NFDM, respectively. The $z$-values of Salmonella and E. faecium found in this study were very close to the $z$-values of Salmonella and E. faecium $\left(16.4\right.$ and $\left.16.5^{\circ} \mathrm{C}\right)$ reported by Liu et al. (2019) and $z$-values of $L$. monocytogenes $\left(14.6\right.$ to $16.0^{\circ} \mathrm{C}$ ) in NFDM at different water activities as reported by Ballom et al. (2020). The determined microbial inactivation kinetics of Salmonella and E. faecium could be a practical tool for the food industry to identify appropriate thermal processing conditions for pasteurization of milk powders.

Tables 2 and 3 show that $D$-values of both microorganisms in NFDM were slightly higher than WMP. Although the initial water activity of both milk powders was equilibrated 0.10 at $25^{\circ} \mathrm{C}$, the water activity 
Log-linear model
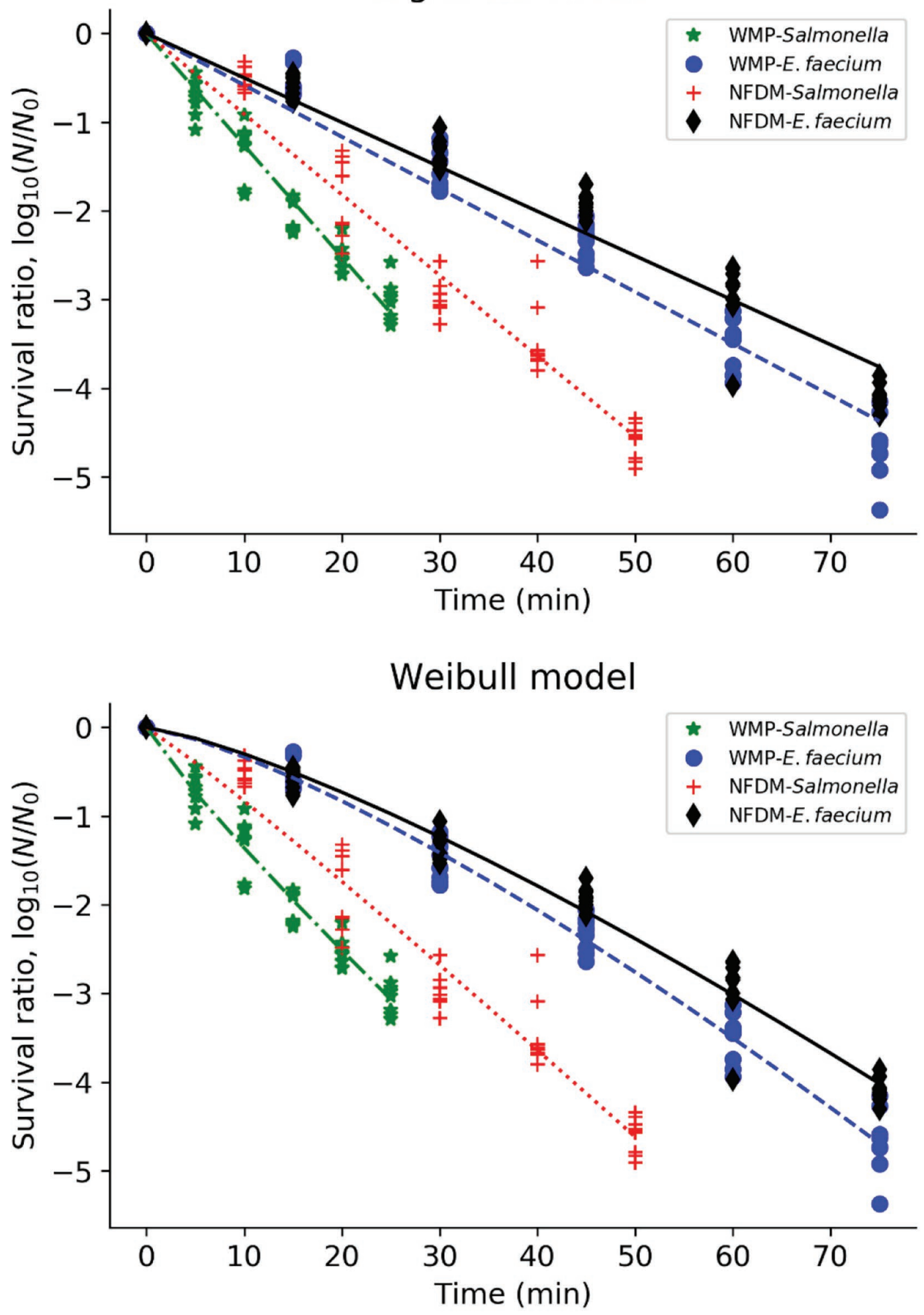

Figure 6. Global log-linear and Weibull models fitted to Salmonella and Enterococcus faecium inactivation data combined across all storage times at $85^{\circ} \mathrm{C}$ at whole milk powder (WMP)-Salmonella ( $\star$, dash-dot line), WMP-E. faecium (•, dashed lines), nonfat dry milk (NFDM)Salmonella (+, dotted lines), and NFDM-E. faecium ( $\bullet$, solid line). $N$ and $N_{0}$ (cfu/g) are the Salmonella or E. faecium survivors at time $t$ and 0. 
at $85^{\circ} \mathrm{C}$ could be different because of differences in the food matrix. As water activity at high temperature plays an important role in thermal inactivation of low-moisture foods, the water activity at $85^{\circ} \mathrm{C}$ for both milk powders may need to be determined to explain the slight differences in $D$-values. Fat has been shown to have a protective effect on high-moisture foods; however, the protective effect of fat in low-moisture foods is not known and need to be investigated in future.

\section{Bacterial Inactivation Model Comparison}

Storage time $(90 \mathrm{~d})$ did not have an effect on the thermal resistance of bacteria in WMP and NFDM. Therefore, the thermal inactivation data at different storage times were combined and globally fitted to both log-linear and Weibull models for model comparison. The $\mathrm{AIC}_{\mathrm{c}}$ and RMSE analysis (Table 4) indicated that the Weibull model was more likely correct (probability $>0.72$ for Salmonella and >0.99 for E. faecium) for all cases. The visualization of the models fitting on the combined data set was shown in Figure 6 .

Several studies have reported that the Weibull model is a better fit than the log-linear model in low water activity food, such as Salmonella in whey protein powder (Farakos et al., 2013), Salmonella in almond kernels (Villa-Rojas et al., 2013), and Listeria monocytogenes and E. faecium in low water activity food powders (Rachon et al., 2016). However, Smith et al. (2016) reported that the log-linear model provided a better prediction than the Weibull model for Salmonella inactivation in wheat flour with minimal difference in $\mathrm{AIC}_{\mathrm{c}}$ values for both models at most water activity levels. In terms of model fitting, the Weibull model was shown to be more suitable than the log-linear model for describing the thermal inactivation of Salmonella and E. faecium in WMP and NFDM.

\section{CONCLUSIONS}

In this study, both Salmonella and E. faecium showed good survivability in WMP and NFDM at low water activity with $<0.9 \log \mathrm{cfu} / \mathrm{g}$ reduction of Salmonella and $<0.2 \mathrm{log} \mathrm{cfu} / \mathrm{g}$ reduction of E. faecium after $90 \mathrm{~d}$ of storage. The thermal resistance of Salmonella and E. faecium did not change significantly during the 90 $\mathrm{d}$ storage of WMP and NFDM. This finding simplifies the process validation study in the industry. Enterococcus faecium was a suitable surrogate for Salmonella at different temperatures $\left(85,90\right.$, and $\left.95^{\circ} \mathrm{C}\right)$. The TDT comparison between Salmonella and E. faecium in milk powders provides an important foundation for the dairy industry for evaluating different thermal treatment technologies that can achieve a suitable reduction of target pathogens. Use of E. faecium, which is a conservative surrogate for process validation, may result in over-processing beyond what is needed for Salmonella reduction, which could affect product quality. Therefore, identifying the kill ratio between Salmonella and E. faecium could contribute to efficient process validations. Based on microbial inactivation kinetics of Salmonella and E. faecium, the food industry could establish an appropriate thermal process validation for pasteurization of milk powders.

\section{ACKNOWLEDGMENTS}

Funding and the milk powder samples for this project were provided by Mars Wrigley (Chicago, IL). The authors have not stated any conflicts of interest.

\section{REFERENCES}

Abd, S. J., K. L. McCarthy, and L. J. Harris. 2012. Impact of storage time and temperature on thermal inactivation of Salmonella Enteritidis PT 30 on oil-roasted almonds. J. Food Sci. 77:M42-M47. https://doi.org/10.1111/j.1750-3841.2011.02439.x.

Almond Board of California. 2014. Guidelines for using Enterococcus faecium NRRL B-2354 as a surrogate microorganism in almond process validation. Accessed Jan. 22, 2019. https://www.almonds .com/sites/default/files/guidelines_for_using_enterococcus _faecium_nrrl_b-2354_as_a_surrogate_microorganism_in _almond_process_validation.pdf.

Angulo, F. J., S. M. Cahill, I. K. Wachsmuth, M. de L. Costarrica, and P. K. B. Embarek. 2008. Powdered infant formula as a source of Salmonella infection in infants. Clin. Infect. Dis. 46:268-273. https: //doi.org/10.1086/524737.

Ballom, K. F., H.-C. Tsai, M. Taylor, J. Tang, and M.-J. Zhu. 2020. Stability of Listeria monocytogenes in non-fat dry milk powder during isothermal treatment and storage. Food Microbiol. 87:103376. https://doi.org/10.1016/j.fm.2019.103376.

Bianchini, A., J. Stratton, S. Weier, T. Hartter, B. Plattner, G. Rokey G. Hertzel, L. Gompa, B. Martinez, and K. M. Eskridge. 2014 Use of Enterococcus faecium as a surrogate for Salmonella enterica during extrusion of a balanced carbohydrate-protein meal. J. Food Prot. 77:75-82. https://doi.org/10.4315/0362-028X.JFP-13-220.

Blessington, T., E. J. Mitcham, and L. J. Harris. 2012. Survival of Salmonella enterica, Escherichia coli O157:H7, and Listeria monocytogenes on inoculated walnut kernels during storage. J. Food Prot. 75:245-254. https://doi.org/10.4315/0362-028X.JFP-11-278.

Blessington, T., C. G. Theofel, and L. J. Harris. 2013. A dry-inoculation method for nut kernels. Food Microbiol. 33:292-297. https:// doi.org/10.1016/j.fm.2012.09.009.

Brouard, C., E. Espié, F.-X. Weill, A. Kérouanton, A. Brisabois, A.M. Forgue, V. Vaillant, and H. de Valk. 2007. Two consecutive large outbreaks of Salmonella enterica serotype Agona infections in infants linked to the consumption of powdered infant formula. Pediatr. Infect. Dis. J. 26:148-152. https://doi.org/10.1097/01.inf .0000253219 .06258 .23 .

Centers for Disease Control and Prevention (CDC). 1998. Multistate outbreak of Salmonella serotype Agona infections linked to toasted oats cereal-United States, April-May, 1998. MMWR Morb. Mortal. Wkly. Rep. 47:462-464.

CDC. 2004. Outbreak of Salmonella serotype Enteritidis infections associated with raw almonds-United States and Canada, 2003-2004. MMWR Morb. Mortal. Wkly. Rep. 53:484-487. https://doi.org/ mm5322a 8 .

CDC. 2007. Multistate outbreak of Salmonella serotype Tennessee infections associated with peanut butter-United States, 2006-2007. 
MMWR Morb. Mortal. Wkly. Rep. 56:521-524. https://doi.org/ mm5621a1.

CDC. 2009. Multistate outbreak of Salmonella Typhimurium infections linked to peanut butter, 2008-2009 (final update). CDC, Atlanta, GA.

CDC. 2010. Salmonella Montevideo infections associated with salami products made with contaminated imported black and red pepper - United States, July 2009-April 2010. MMWR Morb. Mortal. Wkly. Rep. 59:1647-1650. https://doi.org/mm5950a3.

CDC. 2016. Multistate outbreak of Salmonella Reading and Salmonella Abony infections linked to alfalfa sprouts. https://www.cdc .gov/salmonella/reading-08-16/.

CDC. 1993. Salmonella serotype Tennessee in powdered milk products and infant formula-Canada and United States, 1993. MMWR 42:516-517. https://www.cdc.gov/mmwr/preview/mmwrhtml/ 00021081.htm.

Chen, L., X. Wei, S. Irmak, B. D. Chaves, and J. Subbiah. 2019. Inactivation of Salmonella enterica and Enterococcus faecium NRRL B-2354 in cumin seeds by radiofrequency heating. Food Control 103:59-69. https://doi.org/10.1016/j.foodcont.2019.04.004.

de Mendiburu, F., and M. F. de Mendiburu, 2019. Package 'agricolae.' R Package Version, 1-2. R Foundation for Statistical Computing, Vienna, Austria.

Drake, M. A., Y. Karagul-Yuceer, K. R. Cadwallader, G. V. Civille, and P. S. Tong. 2003. Determination of the sensory attributes of dried milk powders and dairy ingredients. J. Sens. Stud. 18:199216. https://doi.org/10.1111/j.1745-459X.2003.tb00385.x.

Farakos, S. M., J. F. Frank, and D. W. Schaffner. 2013. Modeling the influence of temperature, water activity and water mobility on the persistence of Salmonella in low-moisture foods. Int. J. Food Microbiol. 166:280-293. https://doi.org/10.1016/j.ijfoodmicro.2013 .07.007.

Food and Drug Administration (FDA). 2013. FDA draft risk profile: Pathogens and filth in spices. Center for Food Safety and Applied Nutrition, US Department of Health and Human Services, College Park, MD

FDA. 2018. Current good manufacturing practice, hazard analysis, and risk-based preventive controls for human food. Fed. Regist. 21CFR117.135.

Forghani, F., M. den Bakker, J.-Y. Liao, A. S. Payton, A. N. Futral, and F. Diez-Gonzalez. 2019. Salmonella and enterohemorrhagic Escherichia coli serogroups O45, O121, O145 in wheat flour: Effects of long-term storage and thermal treatments. Front. Microbiol. 10:323. https://doi.org/10.3389/fmicb.2019.00323.

Gurtler, J. B., and L. R. Beuchat. 2007. Survival of Enterobacter sakazakii in powdered infant formula as affected by composition, water activity, and temperature. J. Food Prot. 70:1579-1586. https://doi .org/10.4315/0362-028X-70.7.1579

Hildebrandt, I. M., B. P. Marks, E. T. Ryser, R. Villa-Rojas, J. Tang, F. J. Garces-Vega, and S. E. Buchholz. 2016. Effects of inoculation procedures on variability and repeatability of Salmonella thermal resistance in wheat flour. J. Food Prot. 79:1833-1839. https://doi .org/10.4315/0362-028X.JFP-16-057.

Jackson, B. R., P. M. Griffin, D. Cole, K. A. Walsh, and S. J. Chai. 2013. Outbreak-associated Salmonella enterica serotypes and food commodities, United States, 1998-2008. Emerg. Infect. Dis. 19:1239-1244. https://doi.org/10.3201/eid1908.121511.

Jourdan-da Silva, N., L. Fabre, E. Robinson, N. Fournet, A. Nisavanh, M. Bruyand, A. Mailles, E. Serre, M. Ravel, and V. Guibert. 2018. Ongoing nationwide outbreak of Salmonella Agona associated with internationally distributed infant milk products, France, December 2017. Euro Surveill. 23. https://doi.org/10.2807/1560-7917.ES .2018.23.2.17-00852

Jung, Y. S., and L. R. Beuchat. 1999. Survival of multidrug-resistant Salmonella typhimurium DT104 in egg powders as affected by water activity and temperature. Int. J. Food Microbiol. 49:1-8. https: //doi.org/10.1016/S0168-1605(99)00013-6.

Kataoka, A., E. Enache, D. G. Black, P. H. Elliott, C. D. Napier, R. Podolak, and M. M. Hayman. 2014. Survival of Salmonella Tennessee, Salmonella Typhimurium DT104, and Enterococcus faecium in peanut paste formulations at two different levels of water activity and fat. J. Food Prot. 77:1252-1259. https://doi.org/10.4315/0362 -028X.JFP-13-553.

Lau, S. K., and J. Subbiah. 2020a. HumidOSH: A self-contained environmental chamber with controls for relative humidity and fan speed. HardwareX 8:e00141.

Lau, S. K., and J. Subbiah. 2020b. TDT Sandwich: An open source dry heat system for characterizing the thermal resistance of microorganisms. HardwareX 8:e0114. https://doi.org/10.1016/j.ohx 2020.e00114.

Lian, F., W. Zhao, R. Yang, Y. Tang, and W. Katiyo. 2015. Survival of Salmonella enterica in skim milk powder with different water activity and water mobility. Food Control 47:1-6. https://doi.org/ 10.1016/j.foodcont.2014.06.036.

LiCari, J. J., and N. N. Potter. 1970. Salmonella survival during spray drying and subsequent handling of skimmilk powder. III. Effects of storage temperature on Salmonella and dried milk properties. J. Dairy Sci. 53:877-882. https://doi.org/10.3168/jds.S0022 $-0302(70) 86311-1$.

Limcharoenchat, P., M. K. James, and B. P. Marks. 2019. Survival and thermal resistance of Salmonella Enteritidis PT 30 on almonds after long-term storage. J. Food Prot. 82:194-199. https://doi.org/ 10.4315/0362-028X.JFP-18-152.

Liu, S., S. Ozturk, J. Xu, F. Kong, P. Gray, M. Zhu, S. S. Sablani, and J. Tang. 2017. Microbial validation of radio frequency pasteurization of wheat flour by inoculated pack studies. J. Food Eng. 217:68-74

Liu, S., R. V. Rojas, P. Gray, M.-J. Zhu, and J. Tang. 2018. Enterococcus faecium as a Salmonella surrogate in the thermal processing of wheat flour: Influence of water activity at high temperatures. Food Microbiol. 74:92-99. https://doi.org/10.1016/j.fm.2018.03.001.

Liu, S., J. Xu, L. Xie, M.-J. Zhu, and J. Tang. 2019. Dry inoculation methods for nonfat milk powder. J. Dairy Sci. 102:77-86. https:// doi.org/10.3168/jds.2018-14478.

Marler, B. 2018. January 28. France: Powdered Baby Milk Salmonella Outbreak and Recall. Marler Blog. https://www.marlerblog.com/ case-news / france-powdered-baby-milk-salmonella-outbreak-and -recall/.

Motulsky, H. J., and A. Christopoulos. 2003. Fitting models to biological data using linear and nonlinear regression: A practical guide to curve fitting. GraphPad Software Inc., San Diego, CA.

Newville, M., T. Stensitzki, D. Allen, and A. Ingargiola. 2015. Non-linear least-squares minimization and curve-fitting for Python. https: //cars9.uchicago.edu/software/python/lmfit/examples/example fit_with_bounds.html.

Park, J. K., W. S. Seok, B. J. Choi, H. M. Kim, B. K. Lim, S. S. Yoon, S. Kim, Y. S. Kim, and J. Y. Park. 2004. Salmonella enterica serovar London infections associated with consumption of infant formula. Yonsei Med. J. 45:43-48. https://doi.org/10.3349/ ymj.2004.45.1.43.

Peleg, M., and M. B. Cole. 1998. Reinterpretation of microbial survival curves. Crit. Rev. Food Sci. Nutr. 38:353-380. https://doi.org/10 .1080/10408699891274246.

Podolak, R., E. Enache, W. Stone, D. G. Black, and P. H. Elliott. 2010. Sources and risk factors for contamination, survival, persistence, and heat resistance of Salmonella in low-moisture foods. J. Food Prot. 73:1919-1936. https://doi.org/10.4315/0362-028X-73 .10 .1919 .

Rachon, G., W. Peñaloza, and P. A. Gibbs. 2016. Inactivation of Salmonella, Listeria monocytogenes and Enterococcus faecium NRRL B-2354 in a selection of low moisture foods. Int. J. Food Microbiol. 231:16-25. https://doi.org/10.1016/j.ijfoodmicro.2016.04.022.

Rodríguez-Urrego, J., S. Herrera-León, A. Echeita-Sarriondia, P. Soler, F. Simon, and S. Mateo. 2010. Nationwide outbreak of Salmonella serotype Kedougou associated with infant formula, Spain, 2008. Euro Surveill. 15:19582.

Smith, D. F., I. M. Hildebrandt, K. E. Casulli, K. D. Dolan, and B. P. Marks. 2016. Modeling the effect of temperature and water activity on the thermal resistance of Salmonella Enteritidis PT 30 in wheat flour. J. Food Prot. 79:2058-2065. https://doi.org/10.4315/ 0362-028X.JFP-16-155. 
Stapelfeldt, H., B. R. Nielsen, and L. H. Skibsted. 1997. Effect of heat treatment, water activity and storage temperature on the oxidative stability of whole milk powder. Int. Dairy J. 7:331-339. https: //doi.org/10.1016/S0958-6946(97)00016-2.

US Dairy Export Council. 2017. Reference Manual for US Milk Powders. Rev. https://www.thinkusadairy.org/resources-and-insights/ resources-and-insights/product-resources/reference-manual-for-us -milk-powders-and-microfiltered-ingredients.

Verma, T., X. Wei, S. K. Lau, A. Bianchini, K. M. Eskridge, and J. Subbiah. 2018. Evaluation of Enterococcus faecium NRRL B-2354 as a surrogate for Salmonella during extrusion of low-moisture food. J. Food Sci. 83:1063-1072. https://doi.org/10.1111/1750 -3841.14110 .

Villa-Rojas, R., J. Tang, S. Wang, M. Gao, D.-H. Kang, J.-H. Mah, P. Gray, M. E. Sosa-Morales, and A. Lopez-Malo. 2013. Thermal inactivation of Salmonella Enteritidis PT 30 in almond kernels as influenced by water activity. J. Food Prot. 76:26-32. https://doi .org/10.4315/0362-028X.JFP-11-509.

Wei, X., S. K. Lau, B. D. Chaves, M.-G. C. Danao, S. Agarwal, and J. Subbiah. 2020a. Effect of water activity on the thermal inactivation kinetics of Salmonella in milk powders. J. Dairy Sci. 103:69046917. https://doi.org/10.3168/jds.2020-18298.
Wei, X., S. K. Lau, B. S. Reddy, and J. Subbiah. 2020b. A microbial challenge study for validating continuous radio-frequency assisted thermal processing pasteurization of egg white powder. Food Microbiol. 85:103306. https://doi.org/10.1016/j.fm.2019.103306.

Wei, X., S. K. Lau, J. Stratton, S. Irmak, A. Bianchini, and J. Subbiah. 2018. Radio-frequency processing for inactivation of Salmonella enterica and Enterococcus faecium NRRL B-2354 in black peppercorn. J. Food Prot. 81:1685-1695. https://doi.org/10.4315/ 0362-028X.JFP-18-080.

Wei, X., S. K. Lau, J. Stratton, S. Irmak, and J. Subbiah. 2019. Radiofrequency pasteurization process for inactivation of Salmonella spp. and Enterococcus faecium NRRL B-2354 on ground black pepper. Food Microbiol. 82:388-397. https://doi.org/10.1016/j.fm .2019.03.007.

\section{ORCIDS}

Xinyao Wei ำ https://orcid.org/0000-0002-1746-2653

Shantanu Agarwal ( ) https://orcid.org/0000-0001-9412-7130

Jeyamkondan Subbiah @ https://orcid.org/0000-0002-8512-0735 